\title{
Atmosphere pollution modeling in the case of accident during rocket propellant transportation by trains
}

\author{
Mykola Biliaiev ${ }^{1, *}$, Viktoriia Biliaieva ${ }^{2}$, Vitalii Kozachyna ${ }^{1}$, Oleksandr Berlov $^{3}$, Olena Gunko ${ }^{1}$, and Kateryna \\ Chernyatyeva $^{4}$ \\ ${ }^{1}$ DNURT, Department hydraulics and water supply, 49010 Dnipro, Lazaryan Street, 2, Ukraine \\ ${ }^{2}$ DNU, Department aerohydromechanics and energy and masstransfer, 49050 Dnipro, Kozakov Street, 18, Ukraine \\ ${ }^{3}$ PSACEA, Assistant professor of health and safety, 49600 Dnipro, Chernyshevsky Street, 24a, Ukraine \\ ${ }^{4}$ DNURT, Lviv branch, 79052 Lviv, I. Blazhkevich Street, 12a, Ukraine
}

\begin{abstract}
At present time, in Ukraine the intensive development of solid-propellant missiles takes place. These missiles are called «Grim», «Grim-2», etc. Transportation of rocket propellant very often is carried out by trains. In the case of accident during such transportation great amount of toxic chemicals may be emitted into atmosphere. It is very important to predict the atmosphere pollution level near railways transport corridors to obtain the realistic information about the size of possible zones of hitting. To forecast the atmosphere pollution in the case of rocket propellant burning in railway wagon numerical models have been developed. These models are developed to predict the atmosphere pollution in two scales. The first scale is the simulation of the atmosphere pollution near the railway tracks (so called "local scale"). The second scale is the simulation of the atmosphere pollution on the territory which is adjacent to the railway tracks («urban scale»). The forecast is based on the Lagrangian model of toxic chemical dispersion. The models allow also to predict acid rain formation in the case of solid propellant burning products dispersion into atmosphere. To solve the governing equations we used difference schemes of splitting. The results of numerical experiments are presented.
\end{abstract}

\section{Introduction.}

Pavlograd chemical plant (Ukraine) is developing and storing existing rocket propellants. Combustion products of these propellants are highly toxic substances. In case of this propellant burning huge amount of dangerous substances will be emitted in atmosohere. In this regard, an important task is to predict the formation of zones of the atmosphere chemical pollution [3].

It should be noted that for the transportation of solid rocket propellant rail wagons are mainly used (Figures 1, 2).

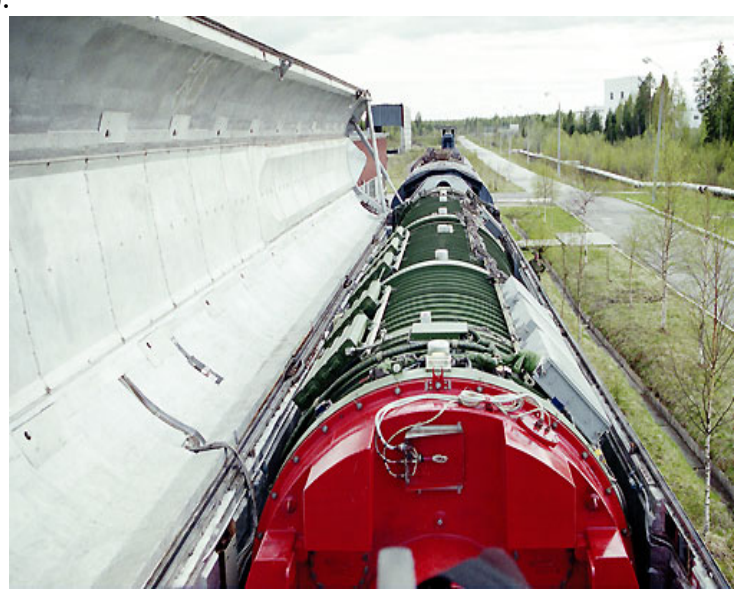

Fig. 1.Solid propellant missile RS-22 in the wagon
Of particular danger are emergencies arisen during the transportation of solid rocket propellant. Transport corridors are situated near small and big cities so the accidental missile solid propellant ignition in the wagon can cause death hitting of residents. So it is important to predict level of danger in case of accidental missile solid propellant ignition in wagon.

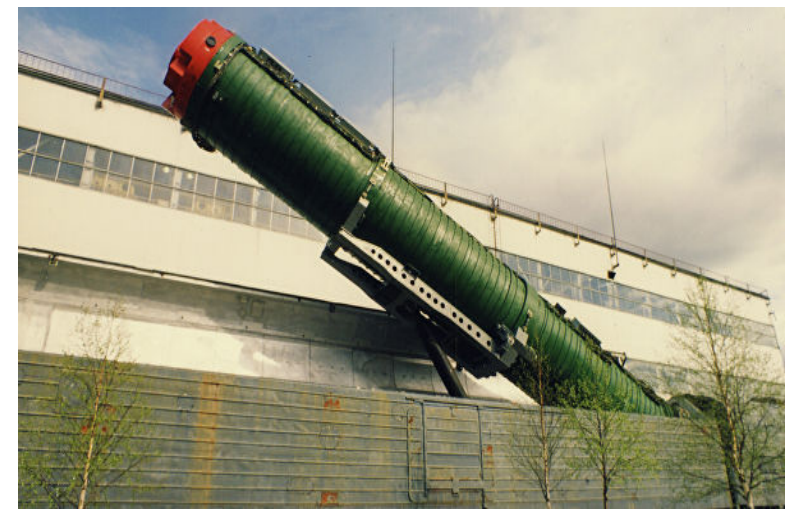

Fig.2. Solid propellant missile RS-22 in the wagon

In assessing the level of air pollution in this case, the following important circumstances should be considered:

1. The train in which solid rocket propellant is being transported cannot immediately stop in the case of a fire in the wagon.

\footnotetext{
* Corresponding author: diit.hydro.eco@gmail.com
} 
2. In assessing the level of air pollution for the considered emergency, it is necessary to take into account that the emission of propellant burning products will occur at a certain time interval (10-15 minutes).

It should be noted that the models used in Ukraine for the prediction of accidental air pollution (for example, the regulatory methodology used in The State Emergency Service of Ukraine or the OND-86 model [6]) do not allow to take into account these circumstances.

To take into account these circumstances, it is necessary to develop specialized mathematical models that would allow to take into account the emission source movement and the time regime of chemically dangerous substances release.

This article describes the mathematical models that have been developed to assess the level of accidental air pollution caused by the solid rocket propellant burning. This work was carried out in cooperation with and commissioned by The State Emergency Service of Ukraine in the Dnipropetrovsk region. The aim of the research is to create mathematical models for assessing the level of air pollution, which take into account the main physical factors influencing the formation of contaminated areas and at the same time requiring little computer time.

\section{Governing equations}

To simulate the process of toxic chemical dispersion in atmosphere (local scale) 3D mass transport equation (equation of toxic chemical dispersion) is used $[1,4,5$, 7]:

$$
\begin{gathered}
\frac{\partial C}{\partial t}+\frac{\partial u C}{\partial x}+\frac{\partial v C}{\partial y}+\frac{\partial w C}{\partial z}+\sigma C= \\
=\frac{\partial}{\partial x}\left(\mu_{x} \frac{\partial C}{\partial x}\right)+\frac{\partial}{\partial y}\left(\mu_{y} \frac{\partial C}{\partial y}\right)+\frac{\partial}{\partial z}\left(\mu_{z} \frac{\partial C}{\partial z}\right)+ \\
+\sum Q_{i}(t) \delta\left(x-x_{i}(t)\right) \delta\left(y-y_{i}(\mathrm{t})\right) \delta\left(z-z_{i}\right)
\end{gathered}
$$

where $u, v, w$ are the velocity components in $x, y$ and $z$ direction respectively; $C$ is the concentration of toxic chemical; $\sigma$ is the parameter taking into account the process of toxic chemical decay or rain wash out;

$\mu_{\mathrm{x}}, \mu_{\mathrm{y}}, \mu_{\mathrm{z}}$ are the coefficients of turbulent diffusion in $x, y$ and $z$ direction respectively; $x_{i}, y_{i}, z_{i}$ are the coordinates of point source of emission; $Q_{i}(t)$ is the intensity of toxic chemical emission; $\delta\left(x-x_{\mathrm{i}}(\mathrm{t})\right) \delta\left(y-y_{\mathrm{i}}(\mathrm{t})\right) \delta\left(z-z_{\mathrm{i}}\right)$ is Dirac delta-function.

Setting the law of $x, y$ coordinates changing in time we simulate the source of emission movement along the railway track. Position of railway track we model by markers in the numerical model.

In the developed numerical model, the following profile of velocity component $u$ and coefficient of diffusion $\mu_{z}$ is used [5]:

$$
u=u_{1}\left(\frac{z}{z_{1}}\right)^{n}, \mu_{z}=k_{1}\left(\frac{z}{z_{1}}\right)^{m},
$$

where $u_{1}$ is the velocity at height $z_{1} ; k_{1}=0,2 ; n=0,16$; $m \approx 1$. The following models to calculate the other diffusive coefficients are used [2]:

$$
\mu_{y}=\mu_{x}, \mu_{y}=k_{0} u,
$$

where $k_{0}$ is the empirical parameter.

The transport equation is used with the following boundary conditions $[1,5]$ :

- inlet boundary: $\left.\mathrm{C}\right|_{\text {inlet }}=C_{E}$, where $C_{E}$ is the known concentration (very often $C_{E}=0$ );

- outlet boundary: in numerical model the condition $C(i+1, j, k)=C(i, j, k)$ is used (this boundary condition means that we neglect the process of diffusion at this plane);

- top boundary and ground surface $\partial \mathrm{C} / \partial \mathrm{n}=0$.

To perform quick predictions of the atmosphere pollution in the case of accidental solid propellant burning in the railway wagon we also used 2D equation of mass transfer to simulate admixture dispersion in urban scale [7]:

$$
\begin{gathered}
\frac{\partial C}{\partial t}+\frac{\partial u C}{\partial x}+\frac{\partial v C}{\partial y}+\sigma C= \\
=\frac{\partial}{\partial x}\left(\mu_{x} \frac{\partial C}{\partial x}\right)+\frac{\partial}{\partial y}\left(\mu_{y} \frac{\partial C}{\partial y}\right)+ \\
+\sum Q_{i}(t) \delta\left(x-x_{i}(t)\right) \delta\left(y-y_{i}(t)\right)
\end{gathered}
$$

where $\sigma$ is the parameter taking into account the process of toxic chemical decay, rain wash out and interaction with earth surface.

We considered burning of propellant for missile "Grim", "Grim-2". According to open access literature, this propellant consists of: ammonium perchlorate, aluminium (Al) and astringent. The solid rocket propellant for missile has very important feature: it could not be exploded. It could only burn during some period of time.

For the case of atmosphere pollution prediction, it is important to know mass of different pollutants which is emitted during rocket propellant burning. To obtain this information, we must know interval of burning, mass of propellant in the wagon and reactions of chemical transformation.

In case of solid propellant burning for missile Grim or Grim - 2 we take into account chemical transformation of one important propellant component $\mathrm{NH}_{4} \mathrm{ClO}_{4}$. In this case the reaction of $\mathrm{NH}_{4} \mathrm{ClO}_{4}$ chemical transformation is as following

$$
2 \mathrm{NH}_{4} \mathrm{ClO}_{4}=\mathrm{Cl}_{2}+\mathrm{O}_{2}+4 \mathrm{H}_{2} \mathrm{O}+2 \mathrm{NO}
$$

If we simulate dispersion in atmosphere products of chemical reaction we solve Eq. (1) or Eq.(2) for each component $\mathrm{Cl}_{2}, \mathrm{NO}$.

\section{Numerical integration}

To develop the numerical models the implicit difference schemes were used. Main features of the scheme for 
numerical integration of 3D equation of toxic chemical dispersion are shown below [7]. First, we split the basic equation of mass transport as following

$$
\begin{gathered}
\frac{\partial C}{\partial t}+\frac{\partial u C}{\partial x}+\frac{\partial v C}{\partial y}+\frac{\partial\left(w-w_{S}\right) C}{\partial z}=0 \\
\frac{\partial C}{\partial t}=\frac{\partial}{\partial x}\left(\mu_{x} \frac{\partial C}{\partial x}\right)+\frac{\partial}{\partial y}\left(\mu_{y} \frac{\partial C}{\partial y}\right)+\frac{\partial}{\partial z}\left(\mu_{z} \frac{\partial C}{\partial z}\right) \\
\frac{\partial C}{\partial t}=\sum Q_{i}(t) \delta\left(x-x_{i}(t)\right) \delta\left(y-y_{i}(t)\right) \delta\left(z-z_{i}\right) .
\end{gathered}
$$
$1]$ :

We represent the convective derivatives as following

$$
\begin{gathered}
\frac{\partial u C}{\partial x}=\frac{\partial u^{+} C}{\partial x}+\frac{\partial u^{-} C}{\partial x}, \frac{\partial v C}{\partial y}=\frac{\partial v^{+} C}{\partial y}+\frac{\partial v^{-} C}{\partial y}, \\
\frac{\partial w C}{\partial z}=\frac{\partial w^{+} C}{\partial z}+\frac{\partial w^{-} C}{\partial z} \\
u^{+}=\frac{u+|u|}{2} ; u^{-}=\frac{u-|u|}{2} ; \\
v^{+}=\frac{v+|v|}{2} ; v^{-}=\frac{v-|v|}{2} ; \\
w^{+}=\frac{w+|w|}{2} ; w^{-}=\frac{w-|w|}{2} .
\end{gathered}
$$

The approximation formulae were as following:

$$
\begin{aligned}
& \frac{\partial}{\partial x}\left(\mu_{x} \frac{\partial C}{\partial x}\right) \approx \mu_{x} \frac{C_{i+1, j, k}^{n+1}-C_{i, j, k}^{n+1}}{\Delta x^{2}}-\mu_{x} \frac{C_{i, j, k}^{n+1}-C_{i-1, j, k}^{n+1}}{\Delta x^{2}}= \\
& =M_{x x}^{-} C^{n+1}+M_{x x}^{+} C^{n+1}, \\
& \frac{\partial}{\partial y}\left(\mu_{y} \frac{\partial C}{\partial y}\right) \approx \mu_{y} \frac{C_{i, j+1, k}^{n+1}-C_{i, j, k}^{n+1}}{\Delta y^{2}}-\mu_{y} \frac{C_{i, j, k}^{n+1}-C_{i, j-1, k}^{n+1}}{\Delta y^{2}}= \\
& =M_{y y}^{-} C^{n+1}+M_{y y}^{+} C^{n+1}, \\
& \frac{\partial}{\partial z}\left(\mu_{z} \frac{\partial C}{\partial z}\right) \approx \mu_{z} \frac{C_{i, j, k+1}^{n+1}-C_{i, j, k}^{n+1}}{\Delta z^{2}}-\mu_{z} \frac{C_{i, j, k}^{n+1}-C_{i, j, k-1}^{n+1}}{\Delta z^{2}}= \\
& =M_{z z}^{-} C^{n+1}+M_{z z}^{+} C^{n+1}, \\
& \frac{\partial u^{+} C}{\partial x} \approx \frac{u_{i+1, j, k}^{+} C_{i, j, k}^{n+1}-u_{i, j, k}^{+} C_{i-1, j, k}^{n+1}}{\Delta x}=L_{x}^{+} C^{n+1} \\
& \frac{\partial u^{-} C}{\partial x} \approx \frac{u_{i+1, j, k}^{-} C_{i+1, j, k}^{n+1}-u_{i, j, k}^{-} C_{i, j, k}^{n+1}}{\Delta x}=L_{x}^{-} C^{n+1} \\
& \frac{\partial v^{+} C}{\partial y} \approx \frac{v_{i, j+1, k}^{+} C_{i, j, k}-v_{i, j, k}^{+} C_{i, j-1, k}}{\Delta y}=L_{y}^{+} C^{n+1} \\
& \frac{\partial v^{-} C}{\partial y} \approx \frac{v_{i, j+1, k}^{-} C_{i, j+1, k}-v_{i, j, k}^{-} C_{i, j, k}}{\Delta y}=L_{y}^{-} C^{n+1} \\
& \frac{\partial w^{+} C}{\partial z} \approx \frac{w_{i, j, k+1}^{+} C_{i, j, k}-w_{i, j, k}^{+} C_{i, j, k-1}}{\Delta z}=L_{z}^{+} C^{n+1}
\end{aligned}
$$

$$
\frac{\partial w^{-} C}{\partial z} \approx \frac{w_{i, j, k+1}^{-} C_{i, j, k+1}-w_{i, j, k}^{-} C_{i, j, k}}{\Delta z}=L_{z}^{-} C^{n+1}
$$

Dependencies to compute concentration on the basis of the first equation from (3) are written as following:

- the first step of splitting $(k=n+1 / 4)$ :

$$
\frac{C_{i, j, k}^{k}-C_{i, j, k}^{n}}{\Delta t}+\frac{1}{2}\left(L_{x}^{+} C^{k}+L_{y}^{+} C^{k}+L_{z}^{+} C^{k}\right)=0 ;
$$

- the second step of splitting $(k=n+1 / 2, c=n+1 / 4)$ :

$$
\frac{C_{i, j, k}^{k}-C_{i, j, k}^{c}}{\Delta t}+\frac{1}{2}\left(L_{x}^{-} C^{k}+L_{y}^{-} C^{k}+L_{z}^{-} C^{k}\right)=0
$$

- the third step of splitting $(k=n+3 / 4, c=n+1 / 2)$ :

$$
\frac{C_{i, j, k}^{k}-C_{i, j, k}^{c}}{\Delta t}+\frac{1}{2}\left(L_{x}^{-} C^{k}+L_{y}^{-} C^{k}+L_{z}^{-} C^{k}\right)=0
$$

- the fourth step of splitting $(k=n+1, c=n+3 / 4)$ :

$$
\frac{C_{i, j, k}^{k}-C_{i, j, k}^{n}}{\Delta t}+\frac{1}{2}\left(L_{x}^{+} C^{k}+L_{y}^{+} C^{k}+L_{z}^{+} C^{k}\right)=0 .
$$

The second equation from (3) was approximated using following formula:

$$
\begin{gathered}
\frac{C_{i, j, k}^{n+1}-C_{i, j, k}^{n}}{\Delta t}=\left[\mu_{x} \frac{C_{i+1, j, k}^{n}-C_{i, j, k}^{n}}{\Delta x^{2}}\right]+\left[\mu_{x} \frac{-C_{i, j, k}^{n}+C_{i-1, j, k}^{n}}{\Delta x^{2}}\right]+ \\
+\left[\mu_{y} \frac{C_{i, j+1, k}^{n}-C_{i, j, k}^{n}}{\Delta y^{2}}\right]+\left[\mu_{y} \frac{-C_{i, j, k}^{n}-C_{i, j-1, k}^{n}}{\Delta y^{2}}\right]+ \\
+\left[\mu_{z} \frac{C_{i, j, k+1}^{n}-C_{i, j, k}^{n}}{\Delta z^{2}}\right]+\left[\mu_{z} \frac{-C_{i, j, k}^{n}+C_{i, j, k-1}^{n}}{\Delta z^{2}}\right] .
\end{gathered}
$$

The approximation formula for the third equation from (3) is:

$$
\begin{aligned}
& C_{i j k}^{n+1}=C_{i j k}^{n+A}+ \\
& +\Delta t \sum Q_{i j k}(t) \delta_{l}\left(x-x_{i}(t)\right) \delta_{l}\left(y-y_{i}(t)\right) \delta_{l}\left(z-z_{i}\right) .
\end{aligned}
$$

For the numerical integration of $2 \mathrm{D}$ equation, the following approach is used. First, we split the differential equation as follows:

$$
\begin{gathered}
\frac{\partial C}{\partial t}+\frac{\partial u C}{\partial x}=\frac{\partial}{\partial x}\left(\mu_{x} \frac{\partial C}{\partial x}\right), \\
\frac{\partial C}{\partial t}+\frac{\partial v C}{\partial y}=\frac{\partial}{\partial y}\left(\mu_{y} \frac{\partial C}{\partial y}\right), \\
\frac{\partial C}{\partial t}+\sigma C=\sum Q_{i}(t) \delta\left(x-x_{i}(t)\right) \delta\left(y-y_{i}(t)\right) .
\end{gathered}
$$

Difference scheme of splitting for first equation from (4) is written as following:

- the first step of splitting: 


$$
\frac{C_{i, j, k}^{k}-C_{i, j, k}^{n}}{\Delta t}+L_{x}^{+} C^{k}=M_{x x}^{+} C^{k}+M_{x x}^{-} C^{n}
$$

- the second step of splitting:

$$
\begin{gathered}
\frac{C_{i, j, k}^{n+1}-C_{i, j, k}^{k}}{\Delta t}+L_{x}^{-} C^{n+1}= \\
=M_{x x}^{+} C^{n}+M_{x x}^{-} C^{n+1} .
\end{gathered}
$$

The difference schemes of splitting for the second equation from (4) are similar. To solve the third equation from (4) we used Euler method.

Worthy of note, that the unknown value of concentration $C$ at every step of splitting in the described difference schemes is carried out using explicit formula of ' running calculation'.

\section{Modeling acid rain formation}

$\mathrm{HCl}$ emission during solid propellant burning results in acid rain formation. Interaction of $\mathrm{HCl}$ with water vapours in the atmosphere results in formation acid drops which fall on the earth. To simulate this process we use the following algorithm:

Step 1. We compute $\mathrm{HCl}$ vapours concentration spreading in the atmosphere at the particular moment of time.

Step 2. We compute of water vapours concentration spreading in the atmosphere at the paticular moment of time.

Step 3. We compute HCL acid amount (mass) with condition that in atmosphere maximum possible acid concentration in solution is $20 \%$.

Step 4. We compute HCL acid migration in the atmosphere on the base of equation (1).

Step 5. We compute $\mathrm{HCl}$ concentration change taking into account that part of $\mathrm{HCl}$ goes to the formation of hydrochloric acid.

Step 6. We compute hydrochloric acid concentration changing in the atmosphere due to its gravity fall out on ground surface. Formula for new hydrochloric acid concentration value in each computation cell at new time moment $(n+1)$ has the following view:

$$
C_{i j}^{n+1}=C_{i j}^{n}-\frac{C_{i j}^{n} \cdot w_{s}}{H} d t
$$

where $C_{i j}^{n}$ is hydrochloric acid concentration in the atmosphere at the moment of time $\mathrm{n} ; C_{i j}^{n+1}$ is hydrochloric acid concentration in the atmosphere at the moment of time $n+1 ; w_{s}$ is speed of hydrochloric acid drops precipitation; $H$ is averaging height; $d t$ is time step.

7. Calculation of hydrochloric acid amount settled on ground surface.

This algorithm was coded in additional subprogram.

\section{Social risk assessment}

Social risk assessment - the risk of toxic damage to people in the residential area - is the final stage in predicting the damage in case of hazardous substances emission.

By risk here we mean the number of people in the zone where the concentration of a toxic chemical exceeds the threshold concentration, which for $\mathrm{HCl}$ is equal or more than $4.5 \mathrm{mg} / \mathrm{m}^{3}$. The developed code includes the subprogram "Hit-2», which calculates where in the region the concentration of the pollutant is equal to or exceeds this threshold value. Based on this data, an array is formed that determines those difference cells that correspond to this concentration. Based on this information, the affected area is built on the map, which allows quickly to assess the size of the area which is dangerous for life.

In addition, this subprogram calculates the number of people who possibly may die in the zone:

$$
D=S_{D}^{\prime} \cdot P,
$$

where $D$ is number of died people; $S_{D}^{\prime}$ is space of the affected area; $P$ is population density.

\section{Results}

We used the developed numerical models to predict $\mathrm{HCl}$ concentrations $(\mathrm{HCl}$ is the product of the solid propellant burning of RC-22 missile) in the case of the accident during its railway transportation. We assumed that at $\mathrm{t}=0$ the solid propellant burning started in the wagon which was moving near Pavlohrad City. The main interest was to compute zones of hitting in the case of moving wagon with burning solid rocket propellant.

The duration of $\mathrm{HCl}$ emission was supposed to be $15 \mathrm{~min}$. The emission rate was $3500 \mathrm{~g} / \mathrm{s}$, the wind speed was $u_{1}=6 \mathrm{~m} / \mathrm{s}$ (we used data of meteorological base, this is typical wind for September, Dnipropetrovsk region, Ukraine). Train speed was $10 \mathrm{~km} / \mathrm{h}$.

The height of the plume that is formed during the propellant burning was calculated using the following empirical model [8]:

$$
h=4,71 \cdot \frac{Q^{0,444}}{u^{0,694}}
$$

where $u$ is wind speed, $Q$ is the intensity of the heat emission.

This vertical plume is simulated as the set of vertical point sources using Delta function.

Figures 3-5 (Dimensions of the computational region are $1,6 \mathrm{~km} \times 1,3 \mathrm{~km}$ ) illustrate formation of contaminated zone near railway track. 


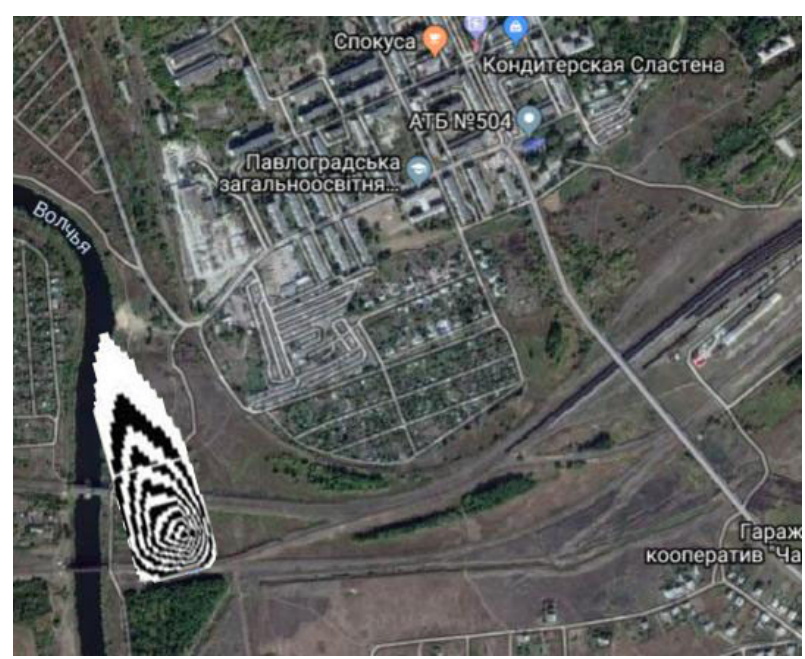

Fig. 3. Contours of $\mathrm{HCl}$ concentration, $\mathrm{t}=3 \mathrm{~min}$ (level $\mathrm{z}=6 \mathrm{~m})$

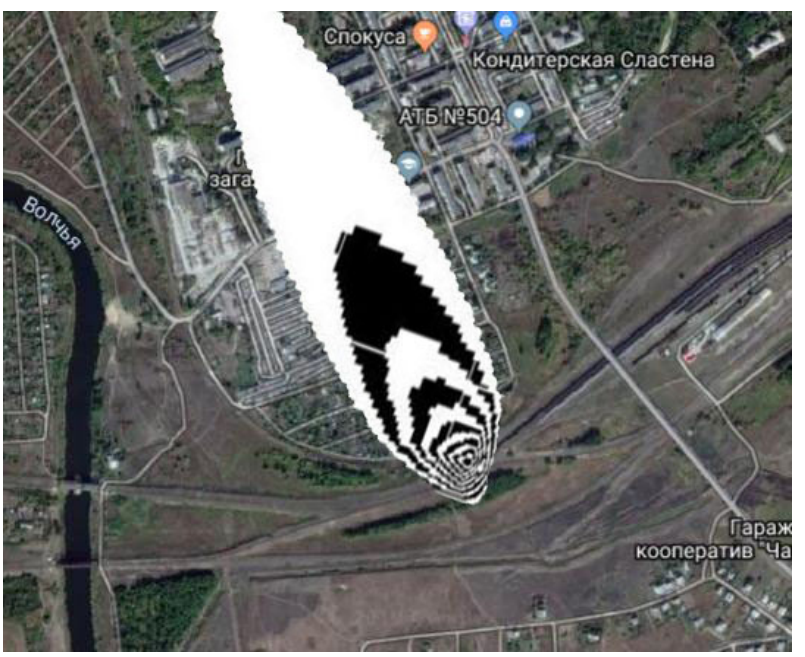

Fig. 4. Contours of $\mathrm{HCl}$ concentration, $\mathrm{t}=9 \mathrm{~min}(\mathrm{level} \mathrm{z}=6 \mathrm{~m})$

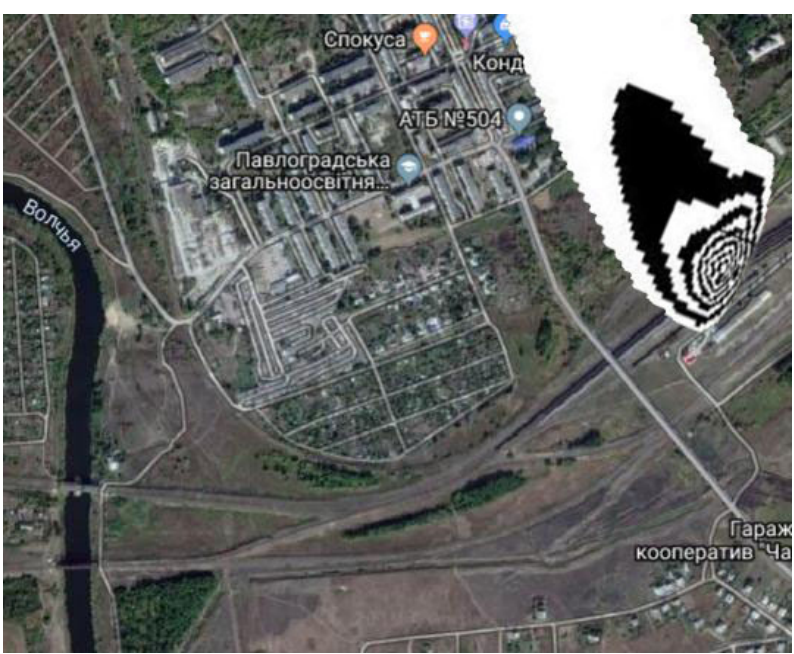

Fig. 5. Contours of $\mathrm{HCl}$ concentration, $\mathrm{t}=14 \mathrm{~min}$ (level $\mathrm{z}=6 \mathrm{~m})$

We see that $\mathrm{HCl}$ plume covers quickly the inhabited territory near the railway track.

In Figures 6-9 (Dimensions of the computational region are $1,1 \mathrm{~km} \times 0,9 \mathrm{~km})$ we present results of numerical simulation of acid rain formation. In this scenario, the wagon with solid rocket propellant was at Pavlohrad Station. The train did not move.

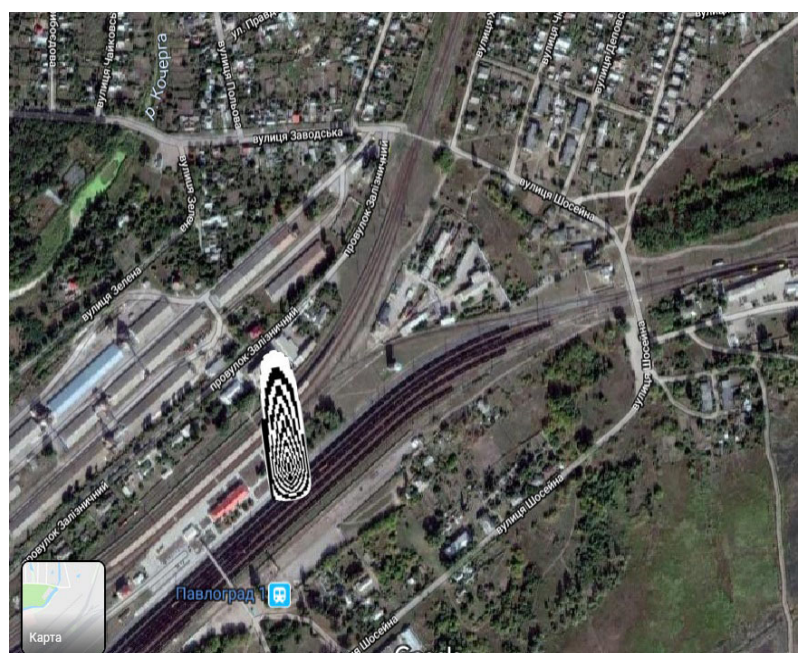

Fig. 6. Contours of $\mathrm{HCl}$ (acid) concentration, $\mathrm{t}=0.7 \mathrm{~min}$ (level $\mathrm{z}=4 \mathrm{~m}$ )

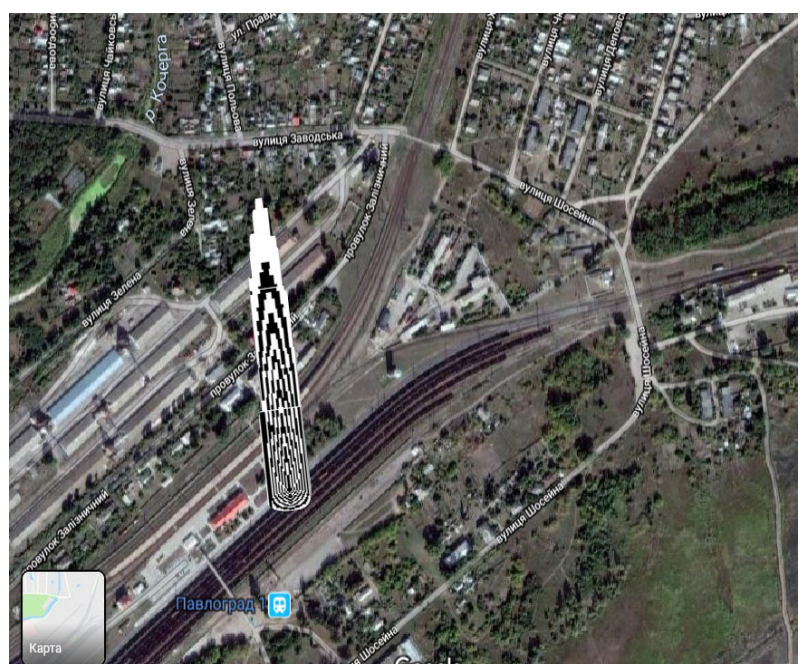

Fig. 7. Contours of $\mathrm{HCl}$ (acid) concentration, $\mathrm{t}=1.8 \mathrm{~min}$ (level $\mathrm{z}=4 \mathrm{~m})$

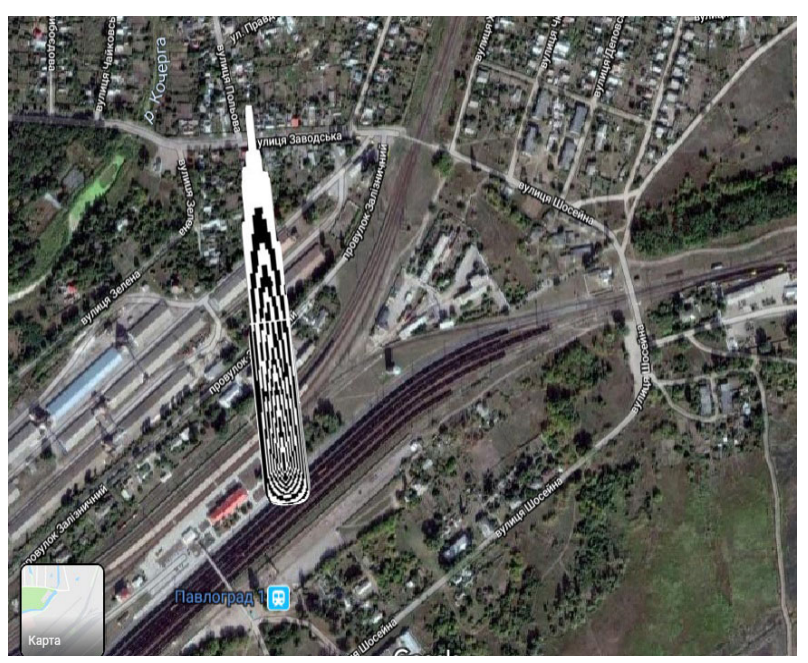

Fig. 8. Contours of $\mathrm{HCl}$ (acid) concentration, $\mathrm{t}=2.2 \mathrm{~min}$ (level $\mathrm{z}=4 \mathrm{~m}$ ) 
As one can see from Figures 6-9 zone of acid contamination is formed very quickly and has the form of «plume». Figures 10, 11 (Dimensions of the computational region are $1,1 \mathrm{~km} \times 0,9 \mathrm{~km}$ ) show hitting zones for different time steps after solid propellant ignition.

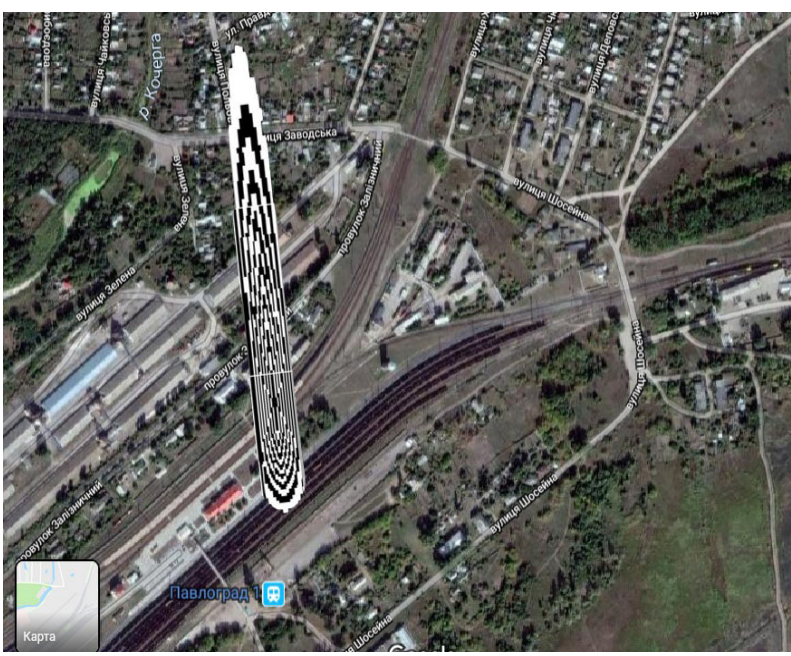

Fig. 9. Contours of $\mathrm{HCl}$ (acid) concentration, $\mathrm{t}=2.5 \mathrm{~min}$ (level $\mathrm{z}=4 \mathrm{~m}$ )

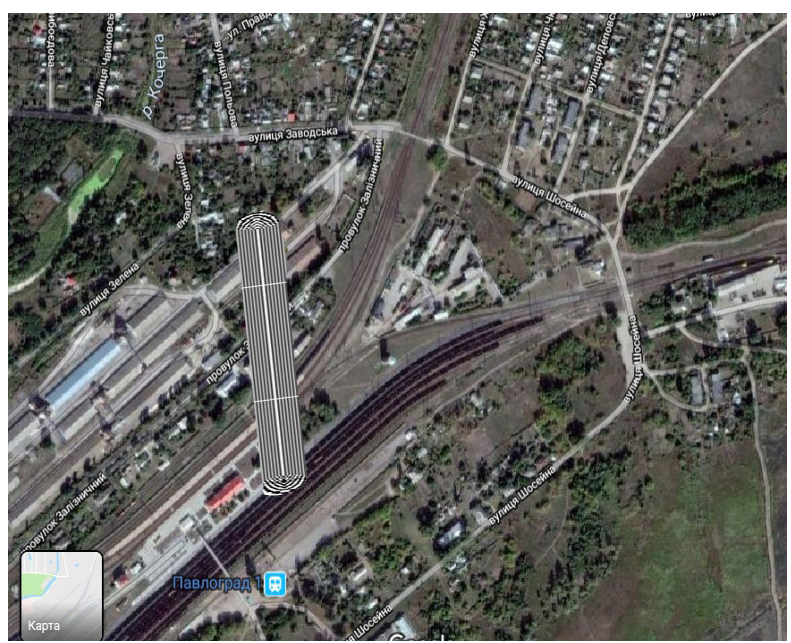

Fig. 10. Zone of dearth hitting, $t=2.1 \mathrm{~min}$

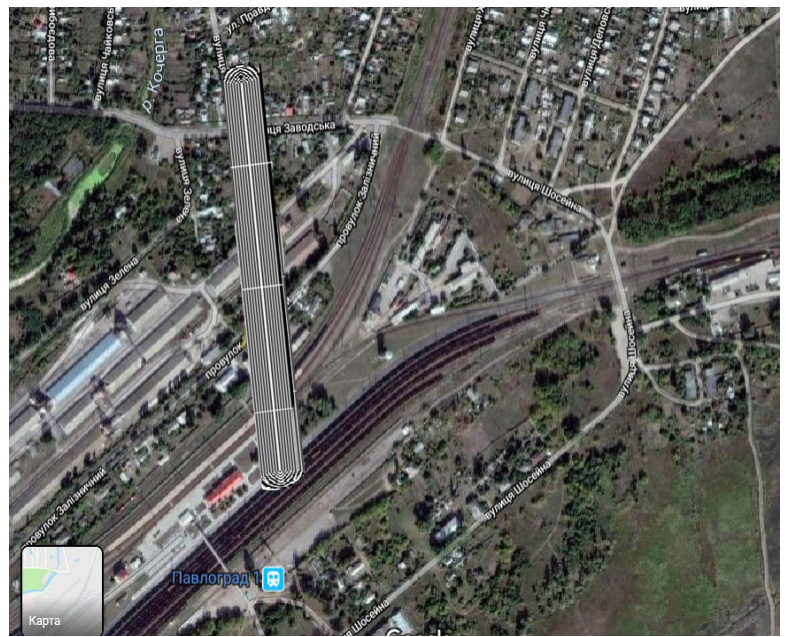

Zones shown in Figures 10, 11 illustrate area where HCL concentration is equal or more than $4.5 \mathrm{mg} / \mathrm{m}^{3}$. In these zones it will be danger for people life.

In case of modeling of another situation, user must make changes in input data block: he must input another wind speed, rate of emission, train speed, etc.

Worthy of note, that computational time was $10 \mathrm{~s}$. It means that the developed numerical model can be used to compute hitting zones near the transport corridors to predict possible damage in case of accidents during transportation of rocket propellant.

The developed numerical model can be used in JSC "Ukrzaliznytsia" to assess risks of toxic hitting in case of accidents with toxic substances during railway transportation.

\section{Conclusions}

The paper shows the mathematical modeling for assessment of pollution level for the case of accident during solid rocket propellant transportation by railway. To compute contamination zones $3 \mathrm{D}$ and $2 \mathrm{D}$ equations of mass transfer are used. These equations take into account the main physical processes, which influence dispersion of toxic chemical in atmosphere. To solve governing equations difference scheme of splitting are used. The unknown value of toxic chemical concentration is calculated using explicit formulae.

Results of numerical simulation show that developed numerical models allow to obtain important information which is necessary in the case of PLAS development (regulatory document in Ukraine which is developed in the case of dangerous cargo transportation).

\section{References}

1. L.I. Antoshkina, Ecological risk assessment in case of emergencies with chemically hazardous substances, (Nauka i obrazovanie, Dnipro, 2008).

2. M.E. Berlyand, Modern problems of atmosphere diffusion and atmosphere pollution, (Gidrometeoizdat, Leninhrad, 1975).

3. M.M. Biliaiev, O.V. Berlov, Cal. of sc. works NGU, 42., 160-167, 2013.

4. M.M. Biliaiev, NATO Science for Peace and Security Series C: Environmental Security, 87-91, (2012).

5. E.V. Bruyatskiy, Theory of atmosphere diffusion of radioactive releases, (Inst. hydromech. NAS of Ukraine, Kyiv, 2000).

6. Method of aftermath assessment of hazardous substances accidental release in case of emergencies at enterprises and transport, (Kyiv, 2001).

7. G.I. Marchuk. Mathematical modeling in environmental problems, (Nauka, Moscow, 1982).

8. K. Uork. Air pollution. Sources and control, (Mir, Moscow, 1980).

Fig. 11. Zone of dearth hitting, $t=2.6 \mathrm{~min}$ 